\title{
Arabidopsis YELLOW STRIPE-LIKE7 (YSL7) and YSL8 Transporters Mediate Uptake of Pseudomonas Virulence Factor Syringolin A into Plant Cells
}

\author{
Silvia Schelbert Hofstetter, Alexey Dudnik, Heidi Widmer, and Robert Dudler \\ Institute of Plant Biology and Zurich-Basel Plant Science Center, University of Zurich, Zollikerstrasse 107, CH-8008 Zurich, \\ Switzerland
}

Submitted 7 June 2013. Accepted 12 July 2013.

\begin{abstract}
Syringolin A (SylA), a virulence factor secreted by certain strains of the plant pathogen Pseudomonas syringae pv. syringae, is an irreversible proteasome inhibitor imported by plant cells by an unknown transport process. Here, we report that functional expression in yeast of all $17 \mathrm{mem}$ bers of the Arabidopsis oligopeptide transporter family revealed that OLIGOPEPTIDE TRANSPORTER1 (OPT1), OPT2, YELLOW STRIPE-LIKE3 (YSL3), YSL7, and YSL8 rendered yeast cells sensitive to growth inhibition by SylA to different degrees, strongly indicating that these proteins mediated SylA uptake into yeast cells. The greatest SylA sensitivity was conferred by YSL7 and YSL8 expression. An Arabidopsis ysl7 mutant exhibited strongly reduced SylA sensitivity in a root growth inhibition assay and in leaves of ysl7 and ysl8 mutants, SylAmediated quenching of salicylic-acid-triggered PATHOGENESIS-RELATED GENE1 transcript accumulation was greatly reduced compared with the wild type. These results suggest that YSL7 and YSL8 are major SylA uptake transporters in Arabidopsis. Expression of a YSL homolog of bean, the host of the SylA-producing $P$. syringae pv. syringae B728a, in yeast also conferred strong SylA sensitivity. Thus, YSL transporters, which are thought to be involved in metal homeostasis, have been hijacked by bacterial pathogens for SylA uptake into host cells.
\end{abstract}

The peptide derivative syringolin A (SylA), a product of a mixed nonribosomal peptide and polyketide synthetase, is secreted by some strains of the phytopathogenic bacterium Pseudomonas syringae pv. syringae in planta (Amrein et al. 2004; Ramel et al. 2009; Wäspi et al. 1998, 1999). Infection experiments on bean plants (Phaseolus vulgaris) revealed SylA to be a virulence factor because inoculation of an SylA-negative mutant caused greatly reduced disease symptoms compared with inoculations with the wild-type Pseudomonas syringae pv. syringae B728a (Groll et al. 2008). The cellular target of SylA was identified to be the proteasome, and it was demonstrated

Corresponding author: R. Dudler; Telephone: ++41 4463482 52; Fax: ++41 4463482 04; E-mail: rdudler@botinst.uzh.ch

* The $\boldsymbol{e}$-Xtra logo stands for "electronic extra" and indicates that three supplementary figures and one supplementary table are published online.

(C) 2013 The American Phytopathological Society that SylA irreversibly inhibited all three catalytic activities of the eukaryotic proteasome by a novel mechanism (Groll et al. 2008). In plants, the proteasome is central in many cellular regulatory processes such as the action of most hormones, including salicylic acid (SA), jasmonic acid (JA), and auxin signal transduction (Dreher and Callis 2007; Santner and Estelle 2010; Vierstra 2009). Thus, inhibition of the proteasome is expected to cause pleiotropic effects. Schellenberg and associates (2010) showed that SylA-producing bacteria counteract stomatal immunity and suppress the SA-dependent defense pathway by SylA-mediated inhibition of the proteasomal turnover of its key regulator, NPR1, which is known to be required for proper function (Spoel et al. 2009).

Many virulence-related factors of bacterial plant pathogens are delivered into host cells by type III secretion systems (Alfano and Collmer 2004; Buttner and Bonas 2002; He et al. 2004). In contrast, SylA is secreted from the bacteria (Amrein et al. 2004; Wäspi et al. 1998) and is thought to be taken up by plant cells through active transport. Indeed, SylA enters the cytoplasm of plant cells very efficiently. Hassa and associates (2000) showed that SylA induces the accumulation of defenserelated transcripts in cultured rice cells at nanomolar concentrations. Because SylA, a hydrophilic peptide derivative readily soluble in water but not in methanol, has a free carboxylic acid group that is assumed to be mostly charged at the slightly acidic $\mathrm{pH}$ found in plant cell walls, uptake into the plant cell is hypothesized to be mediated by peptide transporters or transport facilitators.

Three peptide transporter families have been described in plants (Stacey et al. 2002): i) the ATP-binding cassette (ABC) superfamily, ii) the peptide transporter/nitrate transporter (PTR/NTR) family (Rentsch et al. 2007; Tsay et al. 2007), and iii) the oligopeptide transporter (OPT) family (Koh et al. 2002; Lubkowitz 2011). Members of the ABC transporter family, which in Arabidopsis consists of more than 120 members, hydrolyze ATP to drive transport of substrates ranging from small ions to large macromolecules predominantly out of the cytoplasm (Kang et al. 2011). In contrast, PTR/NTR and OPT are proton-coupled symporters that transport their substrates in the cytosolic direction (Hauser et al. 2000; Osawa et al. 2006; Schaaf et al. 2004). Sequence comparisons identified over 50 putative PTR/NTR genes in the Arabidopsis genome, of which only a few have been functionally characterized (Waterworth and Bray 2006). Whereas some PTR/NTR1 proteins mediate transport of substrates other than peptides (nitrate or carboxylates) (Jeong et al. 2004; Segonzac et al. 2007; Tsay et al. 
2007), Arabidopsis PTR1, PTR2, and PTR3 were described to transport di- and tripeptides when expressed in yeast or Xenopus oocytes (Chiang et al. 2004; Dietrich et al. 2004; Karim et al. 2007; Rentsch et al. 1995; Song et al. 1996), and PTR1 and PTR5 were demonstrated to transport dipeptides in planta (Komarova et al. 2008). Interestingly, PTR1 and PTR2 were also shown to mediate uptake of the bacterial phytotoxin phaseolotoxin, a linear tripeptide derivative, into ptr2 mutant yeast cells upon functional expression of the corresponding Arabidopsis cDNAs (Dietrich et al. 2004).

The Arabidopsis OPT family consists of two distantly related clades: the name-giving OPT group proper, encompassing nine members, and the yellow strike-like (YSL) group of transporters, with eight members. OPT subgroup members were described to transport a broad range of substrates such as tetra- and pentapeptides, the tripeptide glutathione (GSH), GSH conjugates, and metal-chelates (Cagnac et al. 2004; Koh et al. 2002; Pike et al. 2009; Stacey et al. 2008; Vasconcelos et al. 2008), whereas YSL transporters were reported to function as metal-chelate transporters (Chu et al. 2010; Curie et al. 2001, 2009; DiDonato et al. 2004; Divol et al. 2013; Koike et al. 2004; Murata et al. 2006; Roberts et al. 2004; Waters et al. 2006).

Here, we report that, upon expression in yeast, the Arabidopsis transporter genes OPT1, OPT5, YSL3, YSL7, and YSL8 confer SylA sensitivity to yeast cells to different degrees, strongly indicating that they mediate SylA uptake into yeast. Indeed, uptake into YSL7-expressing yeast cells was visualized using rhodamine-coupled SylA. Whereas homozygous opt 1 , opt 5 , and ysl3 mutant Arabidopsis lines showed wild-type sensitivity to SylA with regard to root growth inhibition and SylA responses in leaves, ysl7-1 mutants exhibited considerable SylA insensitivity in roots, and both ysl7-1 and ysl8-1 mutant lines were severely compromised in SylA responses in leaf cells. Furthermore, we show that the YSL homolog Phvul004g138900 of the P. syringae pv. syringae B728a host plant Phaseolus vulgaris mediated SylA sensitivity when functionally expressed in yeast. These results suggest that members of the YSL subfamily are the major SylA uptake transporters in planta.

\section{RESULTS}

\section{Peptides counter SylA inhibition}

of Arabidopsis primary root growth.

To reach its proteasome target, SylA must be taken up by plant cells. Because SylA is a hydrophilic tripeptide derivative, we considered the hypothesis that SylA may be transported into plant cells by peptide transport systems. Therefore, in a competition assay, we tried to counteract Arabidopsis primary root growth inhibition on SylA-containing plates by incorporation of various peptides into the growth medium. Defined peptides ranging in size from di- to 15 -mer peptides were used in plate assays at a 1,000-fold molar excess over the SylA concentration (Fig. 1). As expected, primary root length of seedlings grown on $100 \mathrm{nM}$ SylA-containing plates for 8 days were only approximately $30 \%$ as long as roots grown in control medium (Fig. 1A and B). Reduced primary root growth can be explained by SylA-mediated proteasome inhibition, resulting in the inhibition of cell division in the root meristem and of auxin actions like cell elongation (Groll et al. 2008). Interestingly, tripeptides to octapeptides incorporated into the growth medium were able to counteract root growth inhibition by SylA. We hypothesized that this was due mainly to competition for uptake transport and not for access to proteasome active sites because the peptides alone did not cause a root phenotype (Fig. 1B). If competition was for proteasome access, a phenotype might be expected because endogenous substrates also would likely be competed against. In contrast to 3- to 8-amino-acidlong peptides, neither larger peptides nor the AA dipeptide (IUPAC single-letter amino acid code) were able to reverse SylA-induced root growth inhibition (Fig. 1B). In addition to AA, the dipeptides AN and AK were also tested, with identical results (Supplementary Fig. S1). Furthermore, SylA root phenotype reversal by the modified tripeptide GSH and diverse sugars such as sucrose, the trisaccharide raffinose, and the tetrasaccharide stachyose were examined. Neither GSH nor any of the tested sugars were able to counteract the SylA-mediated root phenotype (Fig. 1B). These data are compatible with the hypothesis that SylA uptake is mediated by plant peptide transporters also accepting tri- to octapeptides but not smaller or
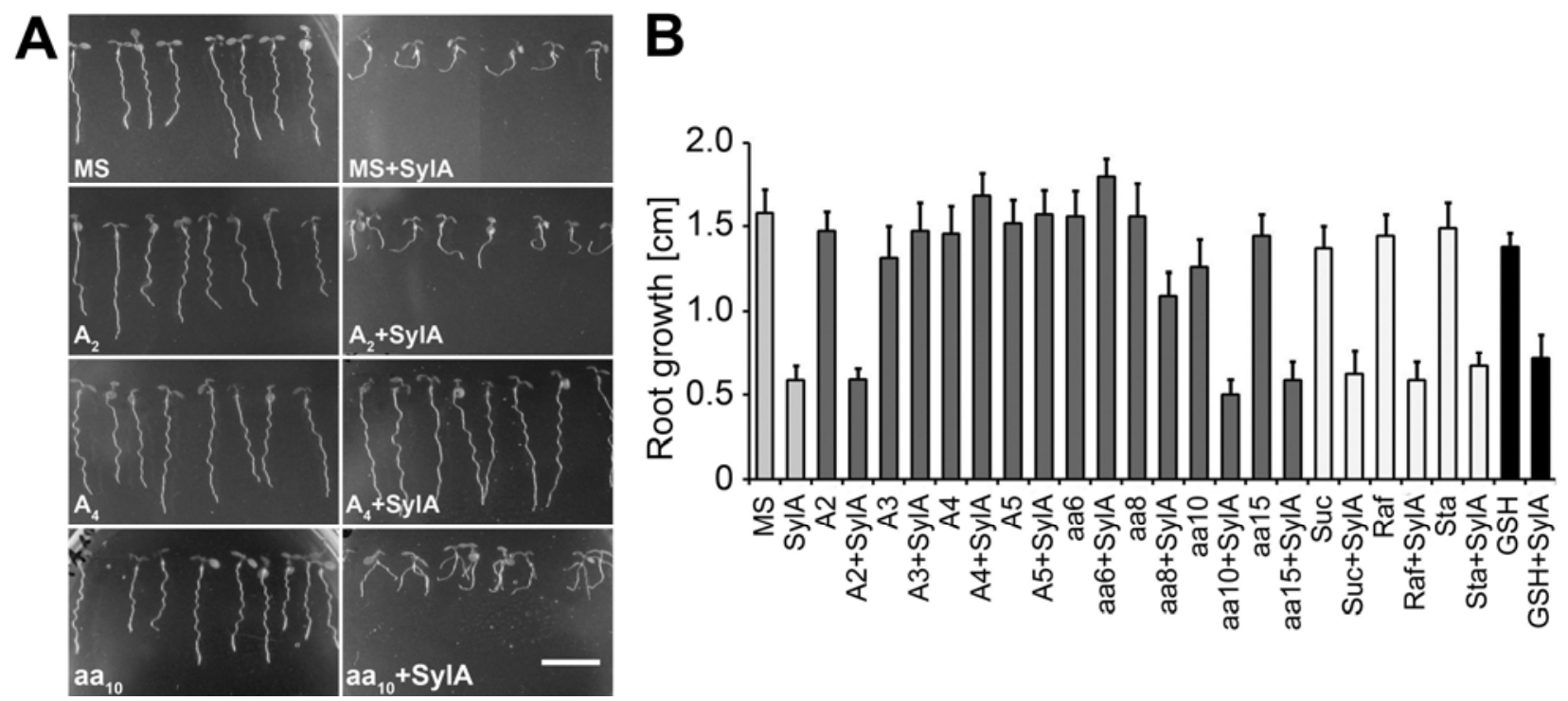

Fig. 1. Peptides compete for syringolin A (SylA) uptake in Arabidopsis roots. Col-0 seed were germinated on vertical plates with or without 100 nM SylA (light gray bars) supplemented with peptides (dark gray bars), sugars (open bars), or glutathione (GSH) (black bars) at concentrations of $100 \mu \mathrm{M}$ for 8 days before primary root length was examined. A, Visual characterization of root growth. Bar $=1 \mathrm{~cm}$. B, Quantification of root length. $\mathrm{A}_{\mathrm{n}}$, alanine

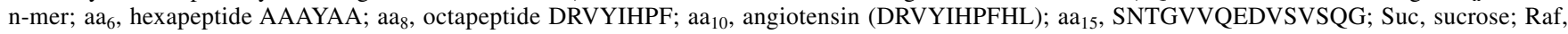
raffinose; Sta, stachyose. Amino acids are given in the one-letter code. Given are mean values $(n=8) \pm$ standard deviation of a representative experiment. 
larger peptides as substrates. Thus, we disregarded the PTR/ NTR family of transporters as candidates for mediating SylA uptake and concentrated on the analysis of OPT and YSL transporters.

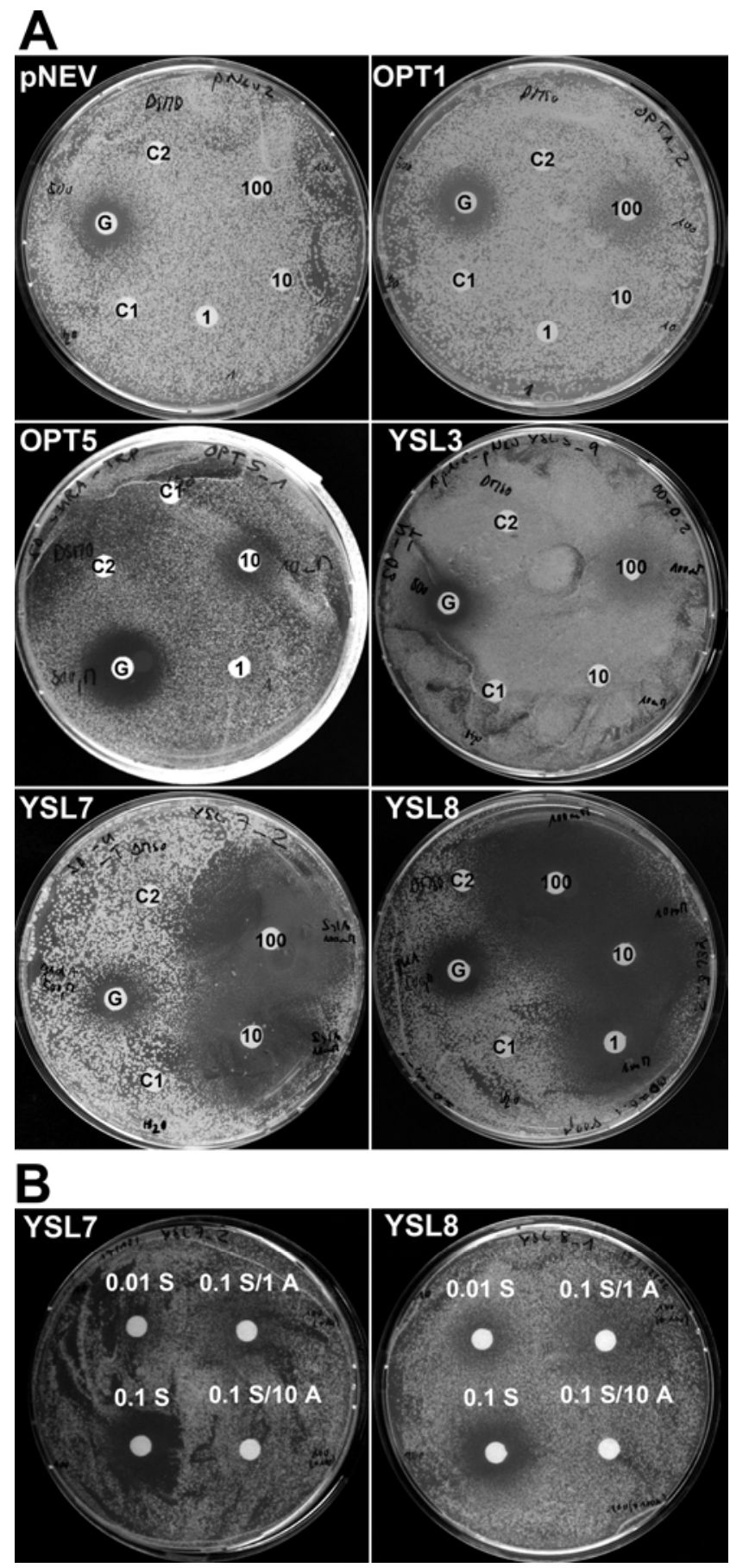

Fig. 2. Syringolin A (SylA)-mediated growth inhibition of yeast. A, Saccharomyces cerevisiae BY4742Apdr5:KanMX6 transformed with the empty vector (pNEV) or vectors expressing the indicated Arabidopsis transporters was plated on solid synthetic defined (SD) minimal medium. Filter disks soaked with 1,10 , or $100 \mathrm{mM}$ SylA solutions were placed onto the plates and inhibition zones were examined after 48 h. G, $500 \mu \mathrm{M}$ glidobactin A; C1, water control; C2, dimethyl sulfoxide control. B, Reversal of SylA-mediated growth inhibition of yeast by $\mathrm{A}_{4}$ tetrapeptide. $S$. cerevisiae strain BY4742 $\Delta$ pdr5:KanMX6 expressing Arabidopsis YSL7 or YSL8 cDNA were plated on solid SD minimal medium. Filter disks soaked in SylA or SylA and $\mathrm{A}_{4}$ peptide solutions of the indicated concentrations $(\mathrm{mM})$ were placed onto the plates and inhibition zones were examined after $48 \mathrm{~h}$. S, SylA; A, A peptide.
Five Arabidopsis OPT mediate

Saccharomyces cerevisiae sensitivity to SylA.

In spite of the fact that SylA covalently binds to the activesite residues of all three catalytic subunits of yeast and other eukaryotic proteasomes in vitro (Groll et al. 2008), the compound was never found to have growth-inhibiting activity against fungal test organisms, including yeast (Wäspi et al. 1998). This is in contrast to the structurally related natural compound glidobactin A (GlbA), which inhibits the eukaryotic proteasome by the same mechanism (Groll et al. 2008) and was originally isolated because of its antifungal and anti-cancer activity (Oka et al. 1988). In contrast to SylA, GlbA exhibits a fatty acid side chain which we hypothesize to be instrumental for uptake into fungal cells. We hypothesized further that the insensitivity of Saccharomyces cerevisiae to SylA was due to the absence of an uptake system, making it an ideal system to express plant genes encoding candidate SylA uptake transporters and to screen transformants for SylA sensitivity by examining growth inhibition.

Thus, full-length cDNAs corresponding to all nine $O P T$ and all eight YSL genes of Arabidopsis were cloned into the yeast expression vector pNEV behind the constitutive PMAl promoter (Nagy et al. 2009). The constructs were transformed into S. cerevisiae BY4742 $\Delta p d r 5: K a n M X 6$, which lacks the ABC multidrug exporter PDR5 (Knop et al. 1999). This drug export mutant was chosen because preliminary experiments showed that it was more sensitive to growth inhibition by GlbA than the wild type. Yeast transformants containing the empty vector or one of the Arabidopsis transporters were plated as a lawn on solid minimal medium and exposed to various concentrations of SylA $(1,10$, and $100 \mathrm{mM})$ on filter disks. GlbA $(500 \mu \mathrm{M})$ dissolved in dimethyl sulfoxide (DMSO) was used as positive control. Inhibition zones around the filter disks were examined after $48 \mathrm{~h}$. As expected, yeast transformants harboring the empty vector ( $\mathrm{pNEV}$ ) showed no growth inhibition around disks with SylA at any concentration, whereas an inhibition zone around filter disks containing $500 \mu \mathrm{M}$ GlbA was visible (Fig. 2A). In contrast, strains transformed with the Arabidopsis OPT1, OPT5, YSL3, YSL7, and YSL8 expression vectors displayed inhibition zones of various diameters around SylA-containing filter disks, suggesting that, indeed, their products mediated SylA uptake into yeast. Whereas Arabidopsis OPT1 and YSL3 cDNAs conferred marginal SylA sensitivity, as indicated by relatively small inhibition zones apparent only around filter disks with $100 \mathrm{mM}$ SylA, OPT5 resulted in a moderate sensitivity visualized by an inhibition zone around a filter disk containing $10 \mathrm{mM}$ SylA. The highest SylA sensitivity was conferred by YSL7 and YSL8, which caused inhibitions zones around filter disks containing SylA concentrations as low as $10 \mu \mathrm{M}$ (Fig. 2A and B). YSL7 and YSL8 exhibited $72 \%$ sequence similarity. The high sensitivity conferred by these two genes was reversed in the presence of a 100-fold molar excess of alanine tetrapeptide over the SylA concentration $\left(100 \mu \mathrm{M}\right.$ SylA versus $\left.10 \mathrm{mM} \mathrm{A}_{4}\right)$ (Fig. 2B). All other transporters did not confer SylA sensitivity to yeast, although presence of approximately equal amounts of transporter transcripts was verified in all transformants by reverse-transcription polymerase chain reaction (RT-PCR) (data not shown). In summary, these results show that expression of Arabidopsis OPT1, OPT5, YSL3, YSL7, and YSL8 rendered yeast cells sensitive to SylA to different degrees, strongly suggesting that their products mediate SylA uptake. We sought to visualize SylA uptake into yeast cells using a rhodamine-coupled SylA derivative (RhSylA). Although this derivative inhibits the proteasome (Clerc et al. 2009) and is able to enter Arabidopsis tissue culture cells (Kolodziejek et al. 2011), it is more hydrophobic than SylA and its molecular mass is more than twofold larger than the one of SylA, properties which may affect 
cellular uptake. Incubation of YSL7-expressing yeast cells in synthetic defined (SD) medium containing $10 \mu \mathrm{M}$ RhSylA for $30 \mathrm{~min}$ led to fluorescent yeast cells (Supplementary Fig. 2), indicating that RhSylA was taken up by these cells. This was in contrast to cells transformed with the empty vector or YSL8expressing cells, which did not take up RhSylA under these conditions. Apparently, YSL7 accepts RhSylA as a substrate, whereas YSL8 does not. This result indicates that YSL7, and probably also YSL8, directly mediate SylA uptake.

\section{A bean YSL homolog also mediates yeast sensitivity to SylA.}

Because bean is the host plant of SylA-producing Pseudomonas syringae pv. syringae $\mathrm{B} 728 \mathrm{a}$, we wanted to elucidate whether bean YSL homologs were also conferring SylA sensitivity to yeast. BLAST searches for YSL7 homologs encoded in the draft genome of Phaseolus vulgaris identified nine YSLrelated proteins. To investigate the relationship between these proteins, we performed a phylogenetic analysis on selected proteins within the BLAST hits which revealed three clades (Fig. 3A). Arabidopsis YSL7 and YSL8 clustered into clade I together with two closely related putative bean proteins (Phvul006g083800 and Phvul004g138900) exhibiting sequence identities of $75 \%$ (AtYSL7 versus Phvul006g083800) and 74\% (AtYSL8 versus Phvul004g138900). In addition, two further
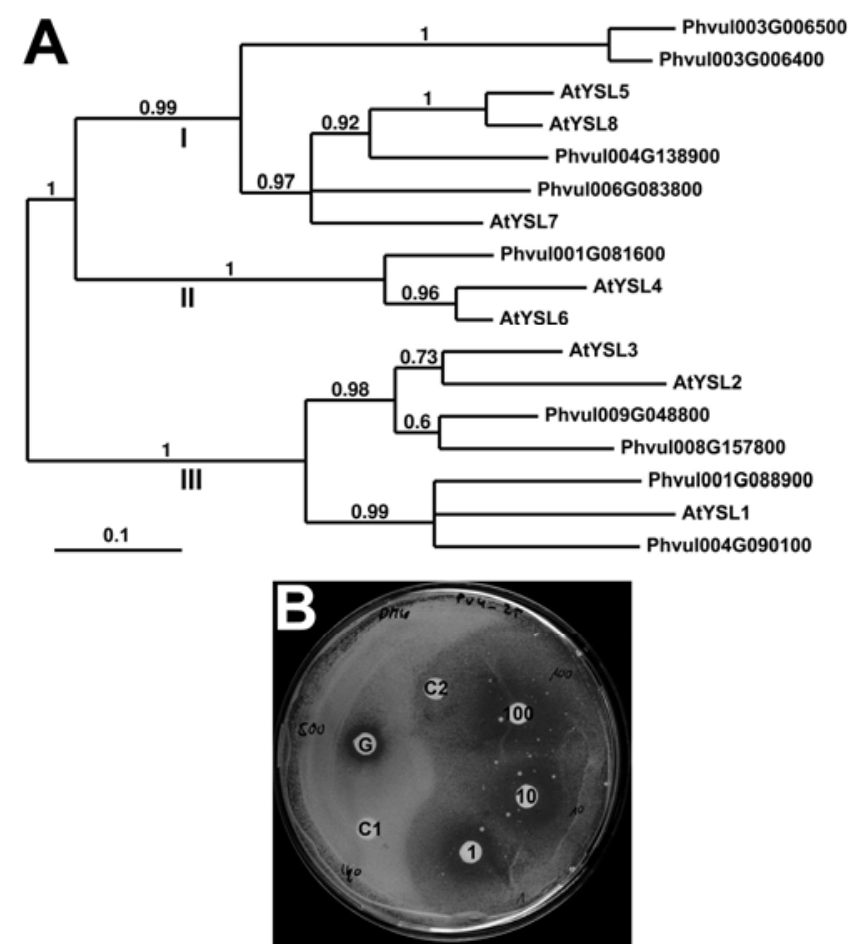

Fig. 3. Bean yellow strike-like (YSL) homolog mediates yeast sensitivity to syringolin A (SylA). A, Phylogenetic relationship between Arabidopsis YSL proteins and bean homologs. Homologs of Arabidopsis YSL7 were identified by BLASTP searches (Altschul et al. 1997) using databases of the joint project of the Department of Energy's Joint Genome Institute and the Center for Integrative Genomics (Goodstein et al. 2012). Phylogenetic analysis was performed using the one-click mode in Phylogeny.fr (Dereeper et al. 2008) using default parameters. Branch support values of the phylogram are based on 100 nonparametric bootstrap replicates. B, Saccharomyces cerevisiae BY4742Apdr5:KanMX6 expressing Phvul004g138900 was uniformly plated on solid synthetic defined minimal medium and exposed to various concentrations of SylA (1, 10, and $100 \mathrm{mM}$ ) on filter disks. The photograph was taken after $48 \mathrm{~h}$. As a positive control, $500 \mu \mathrm{M}$ glidobactin A (G) dissolved in dimethyl sulfoxide (DMSO) was used. C1, water control; C2, DMSO control. The assay was repeated with similar results using an independent yeast transformant.
P. vulgaris proteins (Phvul003g006400 and Phvul003g006500) clustered within the same clade.

To investigate whether proteins encoded by homologous bean YSL genes might function as SylA uptake transporters, a Phvul004g138900 full-length cDNA was cloned and expressed in $S$. cerevisiae BY4742 $\Delta p d r 5:$ KanMX6. Yeast transformants were then subjected to growth inhibition assays as described above. Colonies expressing Phvul004g138900 displayed large inhibition zones around SylA-containing filter disks (Fig. 3B), thus strongly suggesting that Phvul004g138900 mediated SylA uptake into yeast. This result suggests that bean YSL homologs closely related to Arabidopsis YSL7 and YSL8 have a similar physiological function with respect to SylA uptake when exposed to the virulent Pseudomonas syringae pv. syringae B728a pathogen.

\section{Tissue-specific expression and cellular localization} of SylA uptake transporter candidates in Arabidopsis.

The SylA-producing bean pathogen $P$. syringae pv. syringae B728a is a leaf colonizer and, therefore, SylA uptake transporter genes are expected to be expressed in leaves. The tissuespecific expression of $O P T$ and YSL genes which conferred SylA sensitivity to yeast cells was analyzed in Arabidopsis by RT-PCR. The results shown in Figure 4 indicated that, except for $O P T 5$, all transporter genes tested were expressed in leaf tissue, even though some were at low levels. OPT5 was exclusively expressed in flowers and siliques. Thus, OPT5 might play a minor role in SylA uptake into leaf tissue. These results are compatible with microarray data analyzed using Genevestigator (Zimmermann et al. 2004).

Arabidopsis OPT1 and -5, as well as YSL3, -7, and -8 are predicted to be plasma membrane proteins according to the SubCellular Proteomic Database (SUBA3), and their activity in yeast is consistent with the proposed localization, because yeast growth inhibition depended on SylA transport across the plasma membrane (Fig. 2). Arabidopsis YSL3 was previously shown to localize to the plasma membrane of onion epidermal peels (Chu et al. 2010). In order to investigate the subcellular localization of the other four transporters, constructs encoding $\mathrm{N}$-terminal and $\mathrm{C}$-terminal transporter fusions to green fluorescent protein (GFP) were prepared, transformed into Arabidopsis protoplasts, and analyzed by confocal laser-scanning microscopy. Whereas free GFP localized to the cytosol, the N-terminal GFP fusion proteins all gave rise to green fluorescence in the plasma membrane (Fig. 5). We conclude from these results that all Arabidopsis transporters analyzed are located in the plasma

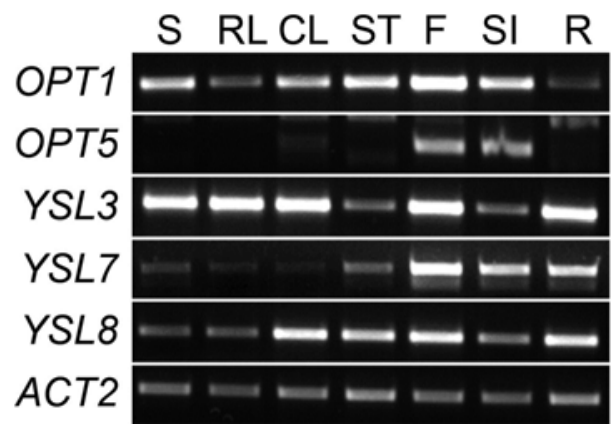

Fig. 4. Tissue-specific expression of Arabidopsis OPT1, OPT5, YSL3, YSL7, and YSL8. Reverse-transcription polymerase chain reaction (PCR) analysis was performed with nonsaturating numbers of PCR cycles using gene-specific primers. ACTIN2 (ACT2) was used as control. Results of one of two independent experiments with similar results are shown. PCR products were separated on agarose gels and visualized with ethidium bromide. S, seedling; RL, rosette leaf; CL, cauline leaf; ST, stem; F, flower; SI, silique; $\mathrm{R}$, root. 
membrane. The respective C-terminal fusions resulted in no fluorescence signal at all (data not shown), possibly due to disrupted protein function or toxicity of the chimeric product.

\section{Arabidopsis ysl7-1 and ysl8-1 mutants exhibit impaired SylA sensitivity.}

Homozygous T-DNA insertion mutants opt1-3, opt5-2, ysl3-1, $y s l 7-1$, and $y s l 8-1$ were obtained and subjected to a root growth assay together with the wild type in order to examine primary root growth inhibition on SylA-containing plates. Similar to the wild type, on SylA-containing plates, roots of all mutants except $y$ s $l 7-1$ reached approximately $25 \%$ of the length observed on control plates (Fig. 6A and B). In contrast, the ysl7-1 mutant exhibited considerable SylA insensitivity because its roots reached $75 \%$ of the length achieved on control plates (Fig. 6B). Nevertheless, some SylA seems to enter roots of ysl7-1 mutants which, in addition to moderately shortened roots, also exhibited somewhat reduced root hair formation (Fig. 6A). This result suggests that YSL7 plays a major role in SylA uptake in roots.

In order to examine the role of the five candidate transporters in SylA uptake in leaves, we made use of the fact that proteasome action is needed for proper function of NPR1, the key regulator of the SA defense pathway (Spoel et al. 2009). As shown previously, spraying of Arabidopsis plants with SylA together with SA leads to greatly reduced SA-induced PATHO-
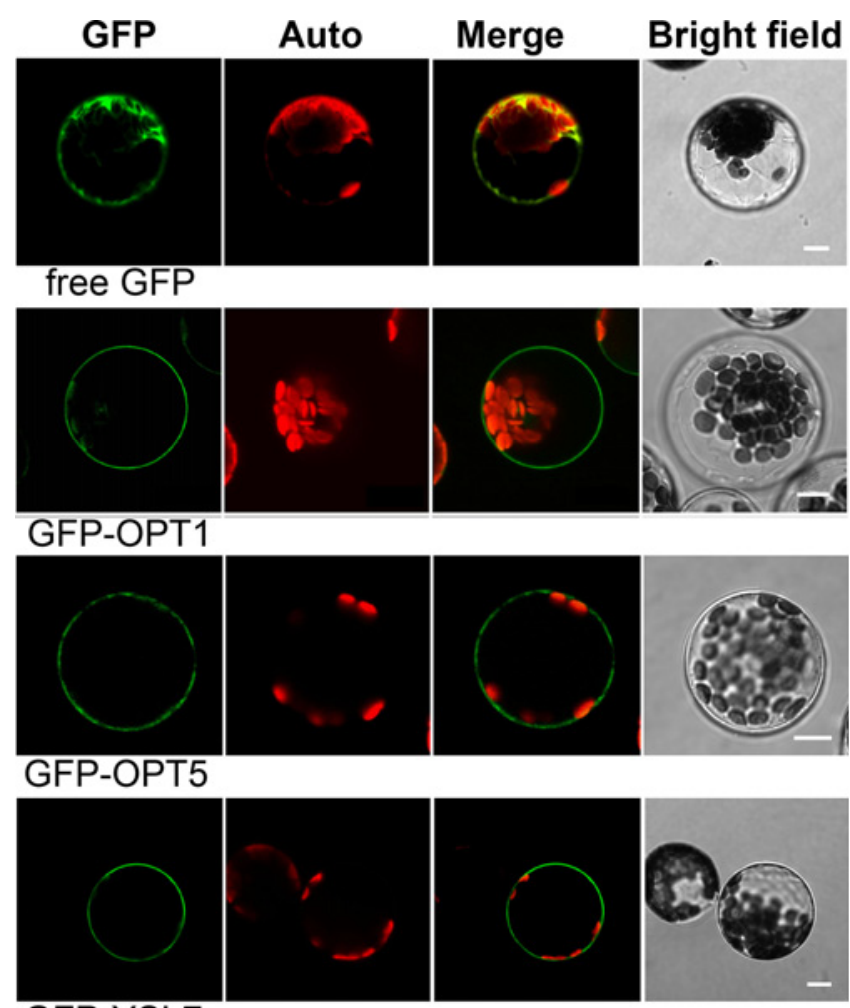

\section{GFP-YSL7}
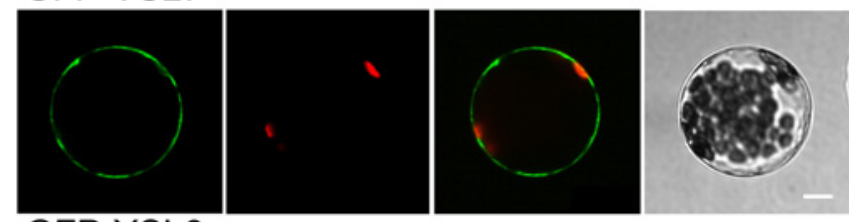

GFP-YSL8

Fig. 5. Analysis of subcellular localization. Transient expression of green fluorescent protein (GFP), GFP-oligopeptide transporter (OPT)1, GFPOPT5, GFP-yellow strike-like (YSL)7, and GFP-YSL8 Arabidopsis protoplasts. GFP fluorescence (GFP) and chlorophyll autofluorescence (Auto) were examined by confocal laser-scanning microscopy. Merge panels show overlays of GFP and autofluorescence recordings. Bars $=10 \mu \mathrm{m}$.
GENESIS-RELATED GENE 1 (PR-1) transcript accumulation compared with spraying with SA alone (Schellenberg et al. 2010). Thus, we used $P R-1$ transcript accumulation as a read out in a similar approach to investigate the involvement of OPT1, OPT5, YSL3, YSL7, and YSL8 in SylA uptake into leaves. Three-week-old Arabidopsis wild-type plants and the respective homozygous mutants were sprayed with $0.05 \%$ Tween 20 solutions containing $2.5 \mathrm{mM}$ SA supplemented with or without $50 \mu \mathrm{M}$ SylA. Total RNA was extracted $18 \mathrm{~h}$ after treatment and subjected to RT-PCR analysis with regard to $P R-1$ transcript accumulation. In the wild type, as expected and shown before (Schellenberg et al. 2010), PR-1 transcript accumulation triggered by SA spraying was greatly diminished by concomitant spraying of SylA (Fig. 6C). In ysl7-1 and ysl8-1 plants, SylA-mediated quenching of SA-induced $P R-1$ transcript accumulation was compromised, whereas all other tested mutant lines showed a $P R-1$ transcript accumulation pattern comparable with that of the wild type (Fig. 6C). Similar results were observed in an independent repetition of the experiment, in which $P R-1$ transcript levels were analyzed by RNA gel blot hybridization with a radiolabeled $P R-1 \mathrm{cDNA}$ probe (Supplementary Fig. S3). Thus, absence of either functional YSL7 or YSL8 resulted in reduced sensitivity to SylA-mediated reduction of SA-triggered $P R-1$ transcript accumulation, strongly suggesting that both transporters play a significant role in SylA uptake into leaf cells. In summary, the results indicate that YSL7 is the major SylA uptake transporter in roots whereas, in leaves, both YSL7 and YSL8 are significantly involved in SylA uptake.

We generated a homozygous ysl7-1 yls $8-1$ double mutant which, however, exhibited a dwarfed phenotype (Fig. 6D) and a strongly reduced fertility. The single double-mutant plant obtained produced approximately 20 seeds in total and developed exceedingly small rosette leaves. When grown on vertical Murashige and Skoog (MS) plates for 10 days, roots of the double mutant were approximately $30 \%$ as long as wild-type roots (Figs. 6E and 5F). On plates containing $250 \mathrm{nM}$ SylA, doublemutant roots produced the longest roots, reaching $56 \%$ of the length observed on plates without SylA. The corresponding values for wild-type and ys $l 7-1$ plants were 7.5 and $14.5 \%$, respectively. Double-mutant plants produced single relatively normal looking primary roots, whereas the $y$ sl7-1 mutant at this SylA concentration developed two or three primary roots that appeared to be somewhat shortened and contorted compared with the double mutant. In this high SylA concentration, the wild type also produced multiple roots which hardly grew, were severely contorted, and displayed a disturbed gravitropism (Fig. 6E). These results show that the double mutant is less sensitive toward SylA than the $y s l 7-1$ mutant but that it is not completely insensitive. In conclusion, our experiments show that members of the YSL transporter subfamily are likely the major SylA uptake transporters in higher plants.

\section{DISCUSSION}

We found that five of the 17 members of the OPT family rendered yeast transformants sensitive to growth inhibition by SylA, indicating that they mediated SylA import. The other family members did not confer SylA sensitivity, although transporter gene transcripts were present in all yeast transformants, as analyzed by RT-PCR. This likely indicates that these transporters do not accept SylA as a substrate. However, it cannot be excluded that insufficient levels of functional transgene product rather than inability to transport SylA played a role.

Yeast transformants expressing OPT1, OPT5, and YSL3 cDNAs displayed only marginal sensitivity toward SylA (Fig. 2). As mentioned above, this may be due to either low SylA 
affinity of the respective transporters or low functional transgene protein product levels. In any case, homozygous opt1, opt5, and ysl3 Arabidopsis mutants exhibited a wild-type phenotype with regard to SylA sensitivity (Fig. 6), thus indicating that the corresponding wild-type genes do not play an essential role in SylA uptake into Arabidopsis root or leaf cells. In contrast, yeast transformants expressing YSL7 and YSL8 were highly sensitive toward SylA, and homozygous ysl7-1 and ysl8-1 mutant Arabidopsis lines showed alleviated SylA-mediated suppression of SA-induced $P R-1$ transcript accumulation, indicating that both wild-type gene products were significantly involved in SylA uptake in leaves. Thus, their function with regard to SylA uptake appears to be at least partially redundant. The fact that both single mutants exhibited an SylA sensitivity phenotype may be interpreted to indicate that the wild-type gene products were limiting SylA uptake with regard to the read out under the experimental conditions used. Earlier microarray hybridization experiments with RNA extracted from Arabidopsis seedlings treated with SylA revealed that none of the YSL genes were induced by SylA (Michel et al. 2006).

In contrast to the leaf assay, where both ysl7-1 and ysl8-1 mutant plants exhibited an SylA response phenotype, ysl8-1 plants were as sensitive to $100 \mathrm{nM}$ SylA as the wild type in the root growth inhibition assay, whereas ysl7-1 plants were insensitive to a considerable degree (Fig. 6A and B). Our RT-PCR data indicated approximately equal expression of both genes in roots (Fig. 4). In a cell and tissue type-specific gene expression map of developing Arabidopsis roots (Birnbaum et al. 2003), YSL7 showed a seven- to eightfold higher expression in lateral root cap cells and a threefold higher expression in the epidermis of stage 1 and stage 2 roots (root tip distal to fully longitudinally expanded cells) compared with other cell types. In contrast, $Y S L 8$ expression was approximately equal in all root cell or tissue types and similar to YSL7 expression in root tissues other than epidermis and lateral root cap (Birnbaum et al. 2003). Thus, the tissue-specific expression of YSL7 in Arabidopsis roots may be instrumental to its function with regard to SylA sensitivity of Arabidopsis roots. YSL8 appears to have a minor role with regard to SylA sensitivity in roots that, however, becomes phenotypically exposed in the ysl7-1 ysl8-1 double mutant. Except for the SylA response phenotype, ysl7-1 and ysl8-1 mutant plants displayed no obvious phenotype difference from that of the wild type. Thus, the biological function of the respective wild-type genes seems to be at least partially redundant.

Genes encoding YSL family proteins have been found in archaea, eubacteria, plants, and fungi, but only for certain plant members has a function been described. The founding
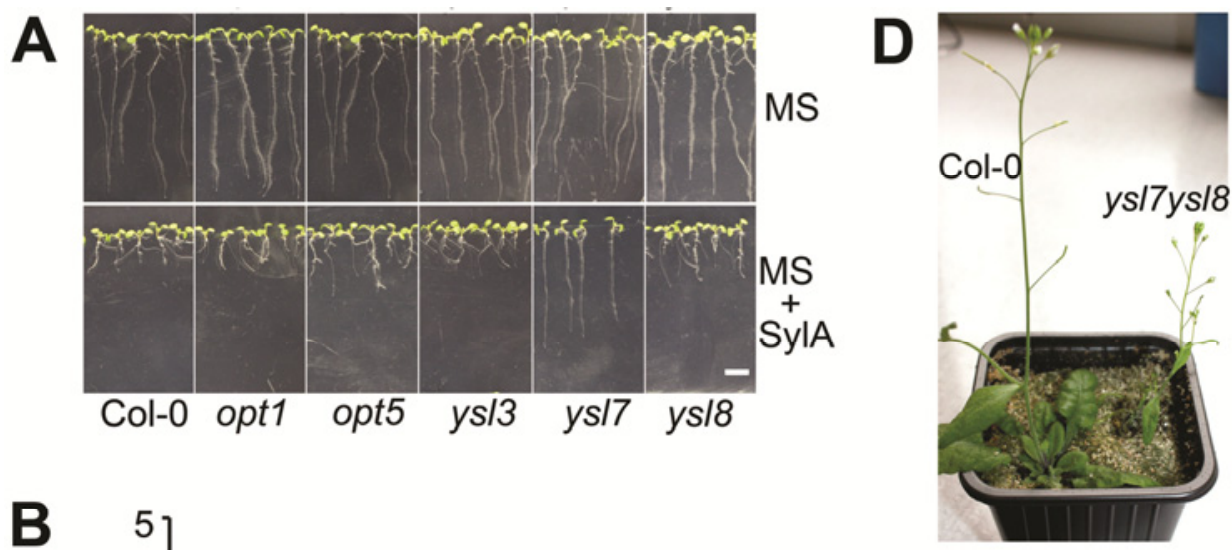

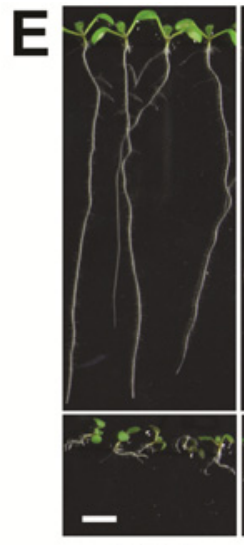

Col-0
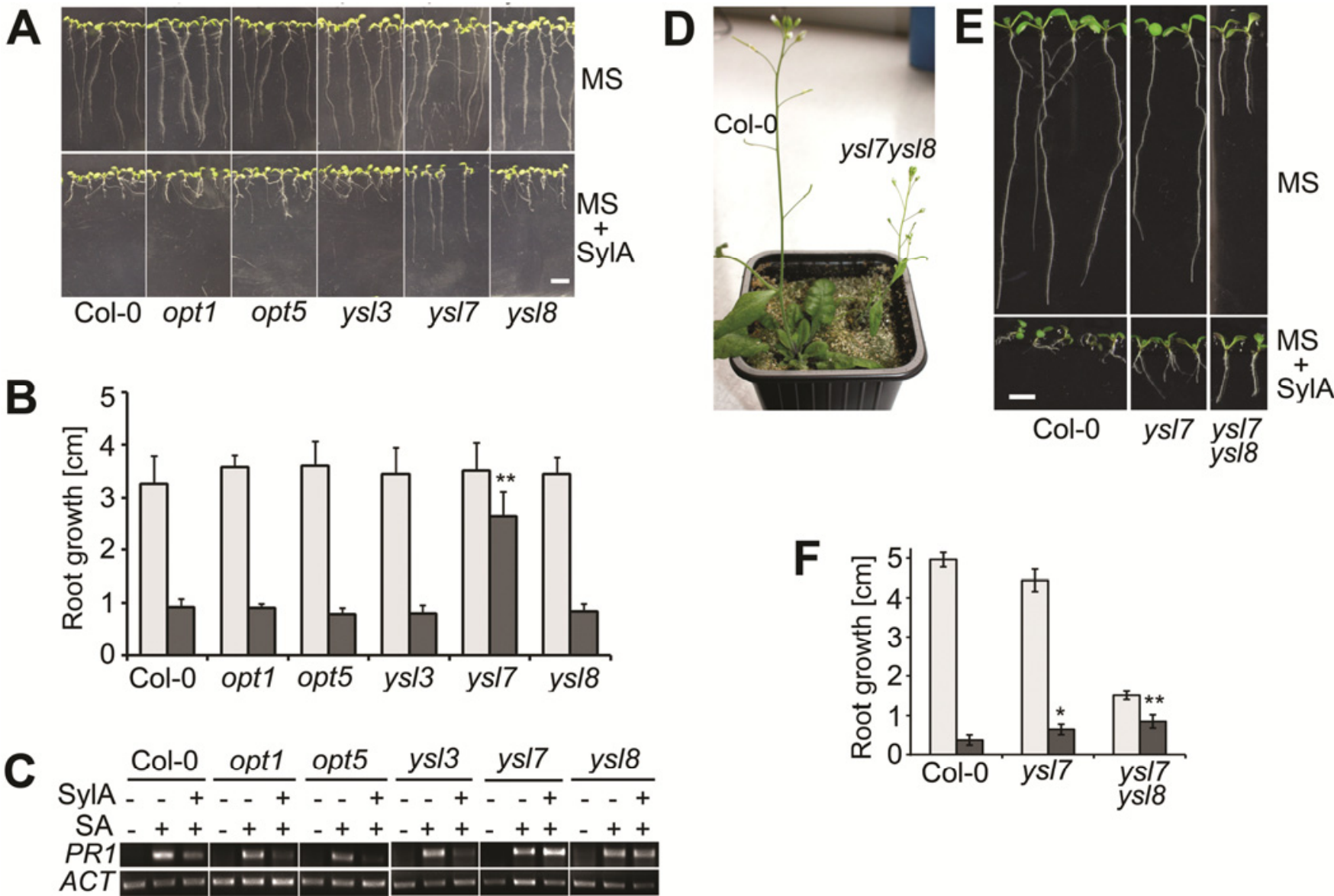

Fig. 6. Yellow strike-like (YSL)7 and YSL8 mediate syringolin A (SylA) sensitivity in Arabidopsis. A, Visual and B, quantified effects of SylA on primary root length of Arabidopsis wild-type and homozygous T-DNA insertion mutants. Seedlings were grown on vertical plates in Murashige and Skoog medium (MS) or medium containing $100 \mathrm{nM}$ SylA (SylA) for 8 days. Data in B are mean values $(n=8) \pm$ standard deviation of a representative experiment. Bar $=$ $0.5 \mathrm{~cm}$. C, Interference of SylA with salicylic acid (SA)-induced PATHOGENESIS-RELATED GENE1 (PR-1) transcript accumulation. Three-week-old Arabidopsis wild-type (Col-0) and homozygous single mutants were sprayed with control buffer supplemented with $2.5 \mathrm{mM}$ SA and $50 \mu \mathrm{M}$ SylA, as indicated. RNA was extracted $18 \mathrm{~h}$ after treatment and $P R-1(P R I)$ transcript abundance was analyzed by semiquantitative reverse-transcription polymerase chain reaction. ACTIN2 (ACT) transcripts were taken as standard. D, Phenotype of 4-week-old Col-0 wild-type and ysl7-1 ysl8-1 double mutant plants grown on soil under long-day conditions. $\mathbf{E}$ and $\mathbf{F}$, Wild-type (Col-0), ysl7-1, and ysl7-1 ysl7-8 seedlings were grown for 9 days on MS medium or medium containing $250 \mathrm{nM}$ SylA (MS+SylA). Data in F are mean values $(n=6) \pm$ standard deviation. Asterisks denote significant root length differences (Student's $t$ test; $*$ and ** indicate $P<0.05$ and 0.01 , respectively) between Col-0 and either $y s l 7-1$ or $y s l 7-1$ ysl8-1 on SylA plates (B and F). 
member YS1 from maize and its orthologs in Poaceae species are part of the primary iron acquisition machinery at the root surface and transport iron-phytosiderophore complexes (Curie et al. 2001; Murata et al. 2006; Schaaf et al. 2004). In dicot plants, YSL proteins are thought to be involved in the transport of various metals complexed with nicotianamine, a chelator structurally related to phytosiderophores (Curie et al. 2009). Although such a transport function has been experimentally demonstrated for Thlaspi caerulescens YSL3 expressed in yeast (Gendre et al. 2007), several Arabidopsis YSL homologs, including the clade III members YSL1 and YSL2 (Fig. 3A), either failed to complement a yeast iron uptake-deficient mutant or results are controversial (Curie et al. 2009; DiDonato et al. 2004; Le Jean et al. 2005; Schaaf et al. 2005). However, roles of YSL1 and YSL3 in metal ion remobilization and distribution in plant tissues and seed as well as in successful reproduction have been demonstrated (Chu et al. 2010; Waters and Grusak 2008; Waters et al. 2006). Recently, YSL4 and YSL6, two members of clade II (Fig. 3), were described to be involved in iron homeostasis of chloroplasts (Divol et al. 2013). In contrast to the other YSL members, YSL6 and probably also YSL4 are localized in chloroplast membranes (Divol et al. 2013).

YSL members of clade I (Fig. 3), to which YSL7 and YSL8 belong, have not been functionally described thus far (Curie et al. 2009), and it is currently not known whether these proteins are also involved in metal homeostatis. Our studies showed that YSL7 and YSL8 are plasma-membrane-localized proteins whose corresponding genes are expressed in diverse tissues (Fig. 4). Furthermore, ysl7-1 ysl8-1 double-mutants have a dwarf phenotype and a strongly reduced fertility. Such a phenotype is not unexpected for plants with an impaired metal homeostasis; thus, it is possible that YSL7 and YSL8 also play a role in metal homeostasis, perhaps using metal-nicotianamine complexes as substrates. Indeed, metal-NA complexes and SylA appear quite similar with regard to chemical properties, size, and net charge. Whatever their biological substrates may be, our results strongly indicate that they transport SylA into plant cells and, hence, that SylA-producing bacteria take advantage of these plant transporters to import the SylA virulence factor into host cells.

SylA and GlbA are the founding members of a novel structural class of proteasome inhibitors termed syrbactins (Groll et al. 2008). The most conspicuous difference between SylA and GlbA is that the extra-cyclic amino acid is attached to an ureido-valine in the case of the hydrophilic SylA, whereas it is acylated with a dodecadienoic acid in GlbA, rendering the latter compound much more hydrophobic. These different tails not only determine the hydrophobicity of the compounds but also how they are taken up into eukaryotic cells. GlbA and its variants are very efficient proteasome inhibitors in mammalian cells (Archer et al. 2010, 2012; Stein et al. 2012) and, thus, are easily imported by an as-yet-unknown uptake system. Conversely, plants are essentially insensitive to GlbA (unpublished observation), most likely because it is not taken up sufficiently well. This observation is in line with the finding that SylA synthetase genes have hitherto only been identified in plant-associated bacteria (i.e., in a number of $P$. syringae pv. syringae strains of genogroup 2 [Baltrus et al. 2011] and in an endophytic rhizobial species [Dudler 2013]), whereas GlbA synthetase genes have been found in a number of animal and human pathogens of the genera Burkholderia and Photorhabdus (Dudler 2013; Dudnik et al. 2013; Schellenberg et al. 2007) but not in plant-associated bacteria. Thus, the different tails of these proteasome inhibitors may be interpreted to represent adaptations to kingdom-specific uptake systems.

\section{MATERIALS AND METHODS}

\section{Plant material and treatment.}

Arabidopsis thaliana ecotype Columbia-0 (Col-0) was used as the wild type. T-DNA insertion lines were from the following collections: SALK (Alonso et al. 2003): At5g55930-3 (opt1-3), SALK_052985; At4g26590-2 (opt5-2), SALK_038178; At5g53550-1 (ysl3-1), SALK_045218; and At1g48370-1 (ysl8-1), SALK_076262; and Gaby line (Rosso et al. 2003): Atlg65730-1 (ysl7-1), GABI_410E06. Lines were obtained from the European Arabidopsis Stock Centre, Nottingham, U.K. Homozygous plants were identified by PCR using T-DNA- and gene-specific primers. Likewise, homozygous ysl7-1 ysl8-1 double-mutants were identified by PCR. Plants were grown on soil in long-day ( $16 \mathrm{~h}$ of light and $8 \mathrm{~h}$ of darkness) conditions in a growth chamber at $21^{\circ} \mathrm{C}$. For protoplast transformation, wildtype plants were grown for 6 weeks at short-day conditions $(8 \mathrm{~h}$ of light and $16 \mathrm{~h}$ of darkness). For root growth assays, seed were surface sterilized in $70 \%$ ethanol with $0.5 \%$ Tween 20 , stratified for $48 \mathrm{~h}$ at $4^{\circ} \mathrm{C}$, and plated on $1 \times$ MS medium containing $0.6 \%$ phytagel and $2 \%$ sucrose with or without $100 \mathrm{nM}$ SylA supplemented with $100 \mu \mathrm{M}$ defined peptides. All peptides except $\mathrm{aa}_{15}$, which was synthesized as described (Dudler et al. 1988), were purchased from Bachem AG, Bubendorf, Switzerland. Plants were germinated on vertical plates under long-day conditions at $21^{\circ} \mathrm{C}$ for 8 to 10 days. SylA and GlbA were isolated as described (Schellenberg et al. 2007; Wäspi et al. 2001).

\section{Cloning of $O P T$ and $Y S L$ cDNAs.}

All primers used in this work are listed in Supplementary Table S1. Full-length cDNAs for Arabidopsis OPT1 (pda02432), OPT3 (pda07074), OPT4 (pda09151), OPT5 (pda02028), and OPT7 (pda01488) were obtained from the RIKEN resource (Seki et al. 2002). OPT2 (DQ446240), OPT6 (C103433), and OPT8 (DQ447070) were obtained from the Arabidopsis Biological Resource Center, Columbus, OH, U.S.A. Full-length cDNAs for OPT9 and YSL1 to YSL8 were obtained by RTPCR. Total RNA was extracted from Arabidopsis wild-type flower or leaf tissue using the SV Total RNA Isolation System (Promega Corp., Madison, WI, U.S.A.) according to the instructions of the manufacturer. First-strand cDNA was synthesized with $1 \mu \mathrm{g}$ of total RNA using M-MLV reverse transcriptase and an oligo(dT) $)_{15}$ primer (Promega Corp.). Full-length cDNAs were amplified using PCR extender polymerase (5Prime, Hamburg, Germany) according to the manufacturer's instructions with gene-specific primers. All PCR fragments except YSL1, YSL2, and YSL3 were cloned into the pGEM-T-easy vector (Promega Corp.) and sequenced. Inserts were cut out with NotI and cloned into the yeast expression vector pNEV (Nagy et al. 2009). Because YSL3 caused lethality in Escherichia coli (Chu et al. 2010), direct cloning in yeast trough homologous recombination (Oldenburg et al. 1997) followed by sequence verification was performed for YSL1, YSL2, and YSL3. In a two-step PCR amplification using PCR extender polymerase (5Prime), 30-nucleotide-long pNEV recombination sites were added. Likewise, Phvul004g138900 cDNA was generated from bean leaves ('Winnetou') using Phusion high-fidelity DNA polymerase (Biolabs) with gene-specific primers and cloned in yeast by homologous recombination (Oldenburg et al. 1997).

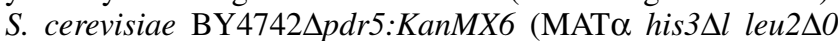

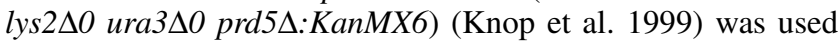
for LiAc/PEG- mediated transformation (Gietz and Schiestl 2007). Yeast transformants were selected on SD minimal medium containing yeast nitrogen base without amino acids at $6.7 \mathrm{~g} \mathrm{liter}^{-1}$, amino acid drop mix at $1 \mathrm{~g} \mathrm{liter}^{-1}$, glucose at $20 \mathrm{~g}$ $\operatorname{liter}^{-1}$, and bactoagar lacking uracil at $20 \mathrm{~g} \mathrm{liter}^{-1}$. Plasmids 
were isolated from positive transformants and all except the ones carrying YSL1, YSL2, YSL3, and Phvul004g138900 cDNAs were retransformed into $E$. coli. NotI enzyme digestions of reisolated plasmids from $E$. coli were used to confirm the cloning of respective peptide transporters in pNEV. Arabidopsis transporter transcript levels in yeast were examined by RT-PCR analysis using gene-specific primer. Total yeast RNA extraction and first-strand cDNA synthesis were performed as described above. As a control, equal amounts of RNA were used as a template to rule out genomic DNA contamination.

\section{SylA sensitivity assay and RhSylA uptake experiments in yeast.}

Yeast transformants expressing Arabidopsis transporters were grown on SD minimal medium lacking uracil and tryptophan to an optical density at $600 \mathrm{~nm}\left(\mathrm{OD}_{600}\right)$ of 0.3 , and $800 \mu \mathrm{l}$ was plated uniformly on solid SD plates lacking uracil and tryptophan. Filter disks (diameter of $5 \mathrm{~mm}$ ) were soaked with water, various concentrations of SylA, or $500 \mu \mathrm{M}$ GlbA dissolved in DMSO and placed on the surface of the plates, which were incubated at $30^{\circ} \mathrm{C}$ for $48 \mathrm{~h}$ before examination.

For RhSylA uptake experiments, yeast transformants containing the empty vector pNEV or expressing YSL7 or YSL8 were grown in SD medium lacking uracil in a shaker at $30^{\circ} \mathrm{C}$ until an $\mathrm{OD}_{600}$ of 1.5. Aliquots of $100 \mu$ were supplemented with rhodamine-coupled SylA at a concentration of $10 \mu \mathrm{M}$ for $30 \mathrm{~min}$. Cells were pelleted $\left(1,700 \times \mathrm{g}, 5 \mathrm{~min}, 4^{\circ} \mathrm{C}\right)$, washed once with $200 \mu \mathrm{l}$ of $1 \mathrm{mM} \mathrm{CaCl}$, and resuspended in the washing solution. Rhodamine fluorescence was observed with a confocal laser-scanning microscope (Leica SP5; excitation $561 \mathrm{~nm}$, emission $570 \mathrm{~nm}$ ). Rhodamine-coupled SylA was a kind gift from Markus Kaiser (Universität Duisburg-Essen, Germany) and was synthesized as described (Clerc et al. 2009).

\section{RNA gel blot and RT-PCR analysis.}

Extraction of total RNA from 2- to 4-week-old wild-type tissues (seedlings, rosette leaves, cauline leaves, stems, flowers, siliques, and roots) and first-strand cDNA synthesis were performed as described above. cDNAs were used to quantify transcript abundance by PCR with nonsaturating numbers of amplification cycles using gene-specific primers.

Three-week-old Arabidopsis wild-type and T-DNA insertion mutants were sprayed with $0.05 \%$ Tween 20 solutions containing $2.5 \mathrm{mM}$ SA supplemented with or without $50 \mu \mathrm{M}$ SylA until droplets started to roll off the leaves. Total RNA was extracted $18 \mathrm{~h}$ after treatment and $5 \mu \mathrm{g}$ of total RNA was subjected to gel blot analysis with a ${ }^{32} \mathrm{P}$-labeled $P R-1$ cDNA hybridization probe (Uknes et al. 1992) using standard procedures (Ausubel et al. 1987).

\section{Localization of GFP fusion proteins.}

Full-length OPT1, OPT5, YSL7, and YSL8 cDNAs were PCR amplified using $P C R$ extender polymerase (5Prime), introducing $S a l \mathrm{I} / S p h \mathrm{I}$ or $S p h \mathrm{I}$ restriction sites for N-terminal GFP fusions, and BamHI/BglII, BamHI/SpeI, or XmaI/SpeI sites for C-terminal GFP fusions, respectively. The PCR fragments were cloned into the pGEM-T-easy vector (Promega Corp.), verified by sequencing, and, after restriction digestion, cloned into pUC18-GFP5T-sp (Meyer et al. 2006), thereby producing an N-terminal fusion with GFP (GFP-YSL). Likewise, for C-terminal fusions (YSL-GFP), PCR fragments were cloned into pUC18-spGFP6 (Meyer et al. 2006). Arabidopsis mesophyll protoplasts were isolated from 6-week-old shortday-grown Col-0 plants according to published procedures (Endler et al. 2006). Protoplasts were adjusted to a density of $2 \times 10^{6}$ per milliliter, transformed with the polyethylene glycol method as described (Meyer et al. 2006), and incubated for $48 \mathrm{~h}$ in the dark at room temperature before GFP fluorescence imaging with a laser-scanning confocal microscope (DM IRE2; Leica Microsystems; excitation at $488 \mathrm{~nm}$, emission recorded between 495 and $530 \mathrm{~nm}$ ). Free GFP expressed from empty pUC18-GFP5T-sp (Meyer et al. 2006) was used as control for cytosolic localization.

\section{ACKNOWLEDGMENTS}

We thank W. P. Tansey (University of Nashville, TN, U.S.A.) for kindly providing yeast strain BY4742 $\Delta$ pdr5:KanMX6, M. Kaiser (University of Duisburg-Essen, Germany) for the gift of RhSylA, and L. Borghi for help with confocal laser-scanning microscopy. This work was supported by grant 31003A-134936 from the Swiss National Science Foundation to R. Dudler, and the University of Zurich.

\section{LITERATURE CITED}

Alfano, J. R., and Collmer, A. 2004. Type III secretion system effector proteins: Double agents in bacterial disease and plant defense. Annu. Rev. Phytopathol. 42:385-414.

Alonso, J. M., Stepanova, A. N., Leisse, T. J., Kim, C. J., Chen, H., Shinn, P., Stevenson, D. K., Zimmermann, J., Barajas, P., and Cheuk, R. 2003. Genome-wide insertional mutagenesis of Arabidopsis thaliana Science 301:653-657.

Altschul, S. F., Madden, T. L., Schaffer, A. A., Zhang, J. H., Zhang, Z., Miller, W., and Lipman, D. J. 1997. Gapped BLAST and PSI-BLAST: A new generation of protein database search programs. Nucleic Acids Res. 25:3389-3402.

Amrein, H., Makart, S., Granado, J., Shakya, R., Schneider-Pokorny, J., and Dudler, R. 2004. Functional analysis of genes involved in the synthesis of syringolin A by Pseudomonas syringae pv. syringae B301D-R. Mol. Plant-Microbe Interact. 17:90-97.

Archer, C. R., Koomoa, D. L. T., Mitsunaga, E. M., Clerc, J., Shimizu, M., Kaiser, M., Schellenberg, B., Dudler, R., and Bachmann, A. S. 2010. Syrbactin class proteasome inhibitor-induced apoptosis and autophagy occurs in association with p53 accumulation and Akt/PKB activation in neuroblastoma. Biochem. Pharmacol. 80:170-178.

Archer, C. R., Groll, M., Stein, M. L., Schellenberg, B., Clerc, J., Kaiser, M., Kondratyuk, T. P., Pezzuto, J. M., Dudler, R., and Bachmann, A. S. 2012. Activity enhancement of the synthetic syrbactin proteasome inhibitor hybrid and biological evaluation in tumor cells. Biochemistry 51:6880-6888.

Ausubel, F. M., Brent, R., Kingston, R. E., Moore, D. D., Smith, J. A., Seidman, J. G., and Struhl, K. 1987. Current Protocols in Molecular Biology. Wiley and Sons, New York.

Baltrus, D. A., Nishimura, M. T., Romanchuk, A., Chang, J. H., Mukhtar, M. S., Cherkis, K., Roach, J., Grant, S. R., Jones, C. D., and Dangl, J. L. 2011. Dynamic evolution of pathogenicity revealed by sequencing and comparative genomics of 19 Pseudomonas syringae isolates. PLoS Pathog. 7:e1002132. Published online.

Birnbaum, K., Shasha, D. E., Wang, J. Y., Jung, J. W., Lambert, G. M., Galbraith, D. W., and Benfey, P. N. 2003. A gene expression map of the Arabidopsis root. Science 302:1956-1960.

Buttner, D., and Bonas, U. 2002. Getting across-bacterial type III effector proteins on their way to the plant cell. EMBO (Eur. Mol. Biol. Organ.) J. 21:5313-5322.

Cagnac, O., Bourbouloux, A., Chakrabarty, D., Zhang, M. Y., and Delrot, S. 2004. AtOPT6 transports glutathione derivatives and is induced by primisulfuron. Plant Physiol. 135:1378-1387.

Chiang, C. S., Stacey, G., and Tsay, Y. F. 2004. Mechanisms and functional properties of two peptide transporters, AtPTR2 and fPTR2. J. Biol. Chem. 279:30150-30157.

Chu, H. H., Chiecko, J., Punshon, T., Lanzirotti, A., Lahner, B., Salt, D. E., and Walker, E. L. 2010. Successful reproduction requires the function of Arabidopsis YELLOW STRIPE-LIKE1 and YELLOW STRIPELIKE3 metal-nicotianamine transporters in both vegetative and reproductive structures. Plant Physiol. 154:197-210.

Clerc, J., Florea, B. I., Kraus, M., Groll, M., Huber, R., Bachmann, A. S., Dudler, R., Driessen, C., Overkleeft, H. S., and Kaiser, M. 2009. Syringolin A selectively labels the $20 \mathrm{~S}$ proteasome in murine EL4 and wildtype and bortezomib-adapted leukaemic cell lines. ChemBioChem 10:2638-2643.

Curie, C., Panaviene, Z., Loulergue, C., Dellaporta, S. L., Briat, J. F., and Walker, E. L. 2001. Maize yellow stripe 1 encodes a membrane protein directly involved in Fe(III) uptake. Nature 409:346-349. 
Curie, C., Cassin, G., Couch, D., Divol, F., Higuchi, K., Jean, M., Misson, J., Schikora, A., Czernic, P., and Mari, S. 2009. Metal movement within the plant: Contribution of nicotianamine and yellow stripe 1-like transporters. Ann. Bot. 103:1-11.

Dereeper, A., Guignon, V., Blanc, G., Audic, S., Buffet, S., Chevenet, F., Dufayard, J. F., Guindon, S., Lefort, V., Lescot, M., Claverie, J. M., and Gascuel, O. 2008. Phylogeny.fr: Robust phylogenetic analysis for the non-specialist. Nucleic Acids Res. 36:W465-W469.

DiDonato, R. J., Roberts, L. A., Sanderson, T., Eisley, R. B., and Walker, E. L. 2004. Arabidopsis Yellow Stripe-Like2 (YSL2): A metal-regulated gene encoding a plasma membrane transporter of nicotianamine-metal complexes. Plant J. 39:403-414.

Dietrich, D., Hammes, U., Thor, K., Suter-Grotemeyer, M., Fluckiger, R. Slusarenko, A. J., Ward, J. M., and Rentsch, D. 2004. AtPTR1, a plasma membrane peptide transporter expressed during seed germination and in vascular tissue of Arabidopsis. Plant J. 40:488-499.

Divol, F., Couch, D., Conejero, G., Roschzttardtz, H., Mari, S., and Curie, C. 2013. The Arabidopsis YELLOW STRIPE LIKE4 and 6 transporters control iron release from the chloroplast. Plant Cell 25:1040-1055.

Dreher, K., and Callis, J. 2007. Ubiquitin, hormones and biotic stress in plants. Ann. Bot. 99:787-822.

Dudler, R. 2013. Manipulation of host proteasomes as a virulence mechanism of plant pathogens. Annu. Rev. Phytopathol. 51:521-542.

Dudler, R., Schmidhauser, C., Parish, R. W., Wettenhall, R. E. H., and Schmidt, T. 1988. A Mycoplasma high-affinity transport-system and the in vitro invasiveness of mouse sarcoma-cells. EMBO (Eur. Mol. Biol. Organ.) J. 7:3963-3970

Dudnik, A., Bigler, L., and Dudler, R. 2013. Heterologous expression of a Photorhabdus luminescens syrbactin-like gene cluster results in production of the potent proteasome inhibitor glidobactin A. Microbiol. Res. 168:73-76.

Endler, A., Meyer, S., Schelbert, S., Schneider, T., Weschke, W., Peters, S. W., Keller, F., Baginsky, S., Martinoia, E., and Schmidt, U. G. 2006. Identification of a vacuolar sucrose transporter in barley and Arabidopsis mesophyll cells by a tonoplast proteomic approach. Plant Physiol. 141:196-207.

Gendre, D., Czernic, P., Conejero, G., Pianelli, K., Briat, J. F., Lebrun, M., and Mari, S. 2007. TcYSL3, a member of the YSL gene family from the hyper-accumulator Thlaspi caerulescens, encodes a nicotianamine$\mathrm{Ni} / \mathrm{Fe}$ transporter. Plant J. 49:1-15.

Gietz, R. D., and Schiestl, R. H. 2007. High-efficiency yeast transformation using the LiAc/SS carrier DNA/PEG method. Nat. Protocols $2: 31-34$

Goodstein, D. M., Shu, S., Howson, R., Neupane, R., Hayes, R. D., Fazo, J., Mitros, T., Dirks, W., Hellsten, U., Putnam, N., and Rokhsar, D. S. 2012. Phytozome: A comparative platform for green plant genomics. Nucleic Acids Res. 40:D1178-D1186.

Groll, M., Schellenberg, B., Bachmann, A. S., Archer, C. R., Huber, R., Powell, T. K., Lindow, S., Kaiser, M., and Dudler, R. 2008. A plant pathogen virulence factor inhibits the eukaryotic proteasome by a novel mechanism. Nature 452:755-758.

Hassa, P., Granado, J., Freydl, E., Wäspi, U., and Dudler, R. 2000. Syringolin-mediated activation of the Pir7b esterase gene in rice cells is suppressed by phosphatase inhibitors. Mol. Plant-Microbe Interact. 13:342 346.

Hauser, M., Donhardt, A. M., Barnes, D., Naider, F., and Becker, J. M. 2000. Enkephalins are transported by a novel eukaryotic peptide uptake system. J. Biol. Chem. 275:3037-3041.

He, S. Y., Nomura, K., and Whittam, T. S. 2004. Type III protein secretion mechanism in mammalian and plant pathogens. Biochim. Biophys. Acta 1694:181-206

Jeong, J. Y., Suh, S., Guan, C. H., Tsay, Y. F., Moran, N., Oh, C. J., An, C. S., Demchenko, K. N., Pawlowski, K., and Lee, Y. 2004. A nodule-specific dicarboxylate transporter from alder is a member of the peptide transporter family. Plant Physiol. 134:969-978.

Kang, J., Park, J., Choi, H., Burla, B., Kretzschmar, T., Lee, Y., and Martinoia, E. 2011. Plant ABC transporters. Page e0153 in: The Arabidopsis Book 9. Published online.

Karim, S., Holmstrom, K. O., Mandal, A., Dahl, P., Hohmann, S., Brader, G., Palva, E. T., and Pirhonen, M. 2007. AtPTR3, a wound-induced peptide transporter needed for defence against virulent bacterial pathogens in Arabidopsis. Planta 225:1431-1445.

Knop, M., Siegers, K., Pereira, G., Zachariae, W., Winsor, B., Nasmyth, K., and Schiebel, E. 1999. Epitope tagging of yeast genes using a PCRbased strategy: More tags and improved practical routines. Yeast 15:963-972.

Koh, S., Wiles, A. M., Sharp, J. S., Naider, F. R., Becker, J. M., and Stacey, G. 2002. An oligopeptide transporter gene family in Arabidopsis. Plant Physiol. 128:21-29.

Koike, S., Inoue, H., Mizuno, D., Takahashi, M., Nakanishi, H., Mori, S., and Nishizawa, N. K. 2004. OsYSL2 is a rice metal-nicotianamine transporter that is regulated by iron and expressed in the phloem. Plant J. 39:415-424.

Kolodziejek, I., Misas-Villamil, J.C., Kaschani, F., Clerc, J., Gu, C. Krahn, D., Niessen, S., Verdoes, M., Willems, L. I., Overkleeft, H. S. Kaiser, M., and van der Hoorn, R. A. L. 2011. Proteasome activity imaging and profiling characterizes bacterial effector syringolin A. Plant Physiol. 155:477-489.

Komarova, N. Y., Thor, K., Gubler, A., Meier, S., Dietrich, D., Weichert, A., Grotemeyer, M. S., Tegeder, M., and Rentsch, D. 2008. AtPTR1 and AtPTR5 transport dipeptides in planta. Plant Physiol. 148:856-869.

Le Jean, M., Schikora, A., Mari, S., Briat, J. F., and Curie, C. 2005. A lossof-function mutation in AtYSL1 reveals its role in iron and nicotianamine seed loading. Plant J. 44:769-782.

Lubkowitz, M. 2011. The oligopeptide transporters: A small gene family with a diverse group of substrates and functions? Mol. Plant 4:407415.

Meyer, A., Eskandari, S., Grallath, S., and Rentsch, D. 2006. AtGAT1, a high affinity transporter for gamma-aminobutyric acid in Arabidopsis thaliana. J. Biol. Chem. 281:7197-7204.

Michel, K., Abderhalden, O., Bruggmann, R., and Dudler, R. 2006. Transcriptional changes in powdery mildew infected wheat and Arabidopsis leaves undergoing syringolin-triggered hypersensitive cell death at infection sites. Plant Mol. Biol. 62:561-578.

Murata, Y., Ma, J. F., Yamaji, N., Ueno, D., Nomoto, K., and Iwashita, T. 2006. A specific transporter for iron(III)-phytosiderophore in barley roots. Plant J. 46:563-572.

Nagy, R., Grob, H., Weder, B., Green, P., Klein, M., Frelet-Barrand, A. Schjoerring, J. K., Brearley, C., and Martinoia, E. 2009. The Arabidopsis ATP-binding cassette protein AtMRP5/AtABCC5 is a high affinity inositol hexakisphosphate transporter involved in guard cell signaling and phytate storage. J. Biol. Chem. 284:33614-33622.

Oka, M., Nishiyama, Y., Ohta, S., Kamei, H., Konishi, M., Miyaki, T., Oki, T., and Kawaguchi, H. 1988. Glidobactins A, B and C, new antitumor antibiotics. I. Production, isolation, chemical properties and biological activity. J. Antibiot. 41:1331-1337

Oldenburg, K. R., Vo, K. T., Michaelis, S., and Paddon, C. 1997. Recombination-mediated PCR-directed plasmid construction in vivo in yeast. Nucleic Acids Res. 25:451-452.

Osawa, H., Stacey, G., and Gassmann, W. 2006. ScOPT1 and AtOPT4 function as proton-coupled oligopeptide transporters with broad but distinct substrate specificities. Biochem. J. 393:267-275.

Pike, S., Patel, A., Stacey, G., and Gassmann, W. 2009. Arabidopsis OPT6 is an oligopeptide transporter with exceptionally broad substrate specificity. Plant Cell Physiol. 50:1923-1932.

Ramel, C., Tobler, M., Meyer, M., Bigler, L., Ebert, M. O., Schellenberg, B., and Dudler, R. 2009. Biosynthesis of the proteasome inhibitor syringolin A: The ureido group joining two amino acids originates from bicarbonate. BMC Biochem. 10:26.

Rentsch, D., Laloi, M., Rouhara, I., Schmelzer, E., Delrot, S., and Frommer, W. B. 1995. NTRl encodes a high-affinity oligopeptide transporter in Arabidopsis. FEBS (Fed. Eur. Biochem. Soc.) Lett. 370:264-268.

Rentsch, D., Schmidt, S., and Tegeder, M. 2007. Transporters for uptake and allocation of organic nitrogen compounds in plants. FEBS (Fed Eur. Biochem. Soc.) Lett. 581:2281-2289.

Roberts, L. A., Pierson, A. J., Panaviene, Z., and Walker, E. L. 2004. Yellow stripe1. Expanded roles for the maize iron-phytosiderophore transporter. Plant Physiol. 135:112-120.

Rosso, M. G., Li, Y., Strizhov, N., Reiss, B., Dekker, K., and Weisshaar, B. 2003. An Arabidopsis thaliana T-DNA mutagenized population (GABIKat) for flanking sequence tag-based reverse genetics. Plant Mol. Biol 53:247-259.

Santner, A., and Estelle, M. 2010. The ubiquitin-proteasome system regulates plant hormone signaling. Plant J. 61:1029-1040.

Schaaf, G., Ludewig, U., Erenoglu, B. E., Mori, S., Kitahara, T., and von Wiren, N. 2004. ZmYS1 functions as a proton-coupled symporter for phytosiderophore- and nicotianamine-chelated metals. J. Biol. Chem. 279:9091-9096.

Schaaf, G., Schikora, A., Haberle, J., Vert, G., Ludewig, U., Briat, J. F., Curie, C., and von Wiren, N. 2005. A putative function for the Arabidopsis Fe-phytosiderophore transporter homolog AtYSL2 in Fe and Zn homeostasis. Plant Cell Physiol. 46:762-774.

Schellenberg, B., Bigler, L., and Dudler, R. 2007. Identification of genes involved in the biosynthesis of the cytotoxic compound glidobactin from a soil bacterium. Environ. Microbiol. 9:1640-1650.

Schellenberg, B., Ramel, C., and Dudler, R. 2010. Pseudomonas syringae virulence factor syringolin a counteracts stomatal immunity by proteasome inhibition. Mol. Plant-Microbe Interact. 23:1287-1293.

Segonzac, C., Boyer, J. C., Ipotesi, E., Szponarski, W., Tillard, P., Touraine, B., Sommerer, N., Rossignol, M., and Gibrat, R. 2007. Nitrate efflux at 
the root plasma membrane: Identification of an Arabidopsis excretion transporter. Plant Cell 19:3760-3777.

Seki, M., Narusaka, M., Kamiya, A., Ishida, J., Satou, M., Sakurai, T., Nakajima, M., Enju, A., Akiyama, K., Oono, Y., Muramatsu, M., Hayashizaki, Y., Kawai, J., Carninci, P., Itoh, M., Ishii, Y., Arakawa, T., Shibata, K., Shinagawa, A., and Shinozaki, K. 2002. Functional annotation of a full-length Arabidopsis cDNA collection. Science 296:141145

Song, W., Steiner, H. Y., Zhang, L., Naider, F., Stacey, G., and Becker, J. M. 1996. Cloning of a second Arabidopsis peptide transport gene. Plant Physiol. 110:171-178.

Spoel, S. H., Mou, Z. L., Tada, Y., Spivey, N. W., Genschik, P., and Dong, X. N. A. 2009. Proteasome-mediated turnover of the transcription coactivator NPR1 plays dual roles in regulating plant Immunity. Cell 137:860-872.

Stacey, G., Koh, S., Granger, C., and Becker, J. M. 2002. Peptide transport in plants. Trends Plant Sci. 7:257-263.

Stacey, M. G., Patel, A., McClain, W. E., Mathieu, M., Remley, M., Rogers, E. E., Gassmann, W., Blevins, D. G., and Stacey, G. 2008. The Arabidopsis AtOPT3 protein functions in metal homeostasis and movement of iron to developing seeds. Plant Physiol. 146:589-601.

Stein, M. L., Beck, P., Kaiser, M., Dudler, R., Becker, C. F. W., and Groll, M. 2012. One-shot NMR analysis of microbial secretions identifies highly potent proteasome inhibitor. Proc. Natl. Acad. Sci. U.S.A. 109:18367-18371.

Tsay, Y. F., Chiu, C. C., Tsai, C. B., Ho, C. H., and Hsu, P. K. 2007. Nitrate transporters and peptide transporters. FEBS (Fed. Eur. Biochem. Soc.) Lett. 581:2290-2300.

Uknes, S., Mauchmani, B., Moyer, M., Potter, S., Williams, S., Dincher, S., Chandler, D., Slusarenko, A., Ward, E., and Ryals, J. 1992. Acquiredresistance in Arabidopsis. Plant Cell 4:645-656.

Vasconcelos, M. W., Li, G. W., Lubkowitz, M. A., and Grusak, M. A. 2008. Characterization of the pt clade of oligopeptide transporters in rice. Plant Genome 1:77-88.

Vierstra, R. D. 2009. The ubiquitin-26S proteasome system at the nexus of plant biology. Nat. Rev. Mol. Cell Biol. 10:385-397.

Wäspi, U., Blanc, D., Winkler, T., Ruedi, P., and Dudler, R. 1998. Syringolin, a novel peptide elicitor from Pseudomonas syringae pv. syringae that induces resistance to Pyricularia oryzae in rice. Mol. Plant-Microbe Interact. 11:727-733.

Wäspi, U., Hassa, P., Staempfli, A. A., Molleyres, L. P., Winkler, T., and Dudler, R. 1999. Identification and structure of a family of syringolin variants: Unusual cyclic peptides from Pseudomonas syringae pv. syringae that elicit defense responses in rice. Microbiol. Res. 154:89-93.

Wäspi, U., Schweizer, P., and Dudler, R. 2001. Syringolin reprograms wheat to undergo hypersensitive cell death in a compatible interaction with powdery mildew. Plant Cell 13:153-161.

Waters, B. M., and Grusak, M. A. 2008. Whole-plant mineral partitioning throughout the life cycle in Arabidopsis thaliana ecotypes Columbia, Landsberg erecta, Cape Verde Islands, and the mutant line ysl1ysl3. New Phytol. 177:389-405.

Waters, B. M., Chu, H. H., DiDonato, R. J., Roberts, L. A., Eisley, R. B., Lahner, B., Salt, D. E., and Walker, E. L. 2006. Mutations in Arabidopsis YELLOW STRIPE-LIKE1 and YELLOW STRIPE-LIKE3 reveal their roles in metal ion homeostasis and loading of metal ions in seeds. Plant Physiol. 141:1446-1458.

Waterworth, W. M., and Bray, C. M. 2006. Enigma variations for peptides and their transporters in higher plants. Ann. Bot. 98:1-8.

Zimmermann, P., Hirsch-Hoffmann, M., Hennig, L., and Gruissem, W. 2004 GENEVESTIGATOR. Arabidopsis microarray database and analysis toolbox. Plant Physiol. 136:2621-2632.

\section{AUTHOR-RECOMMENDED INTERNET RESOURCES}

Joint Genome Institute and the Center for Integrative Genomics phytozome database: www.phytozome.org

Phylogeny.fr, a phylogenetic analysis database: www.phylogeny.fr

The University of Western Australia's SUBcellular localization database for Arabidopsis proteins: suba.plantenergy.uwa.edu.au 